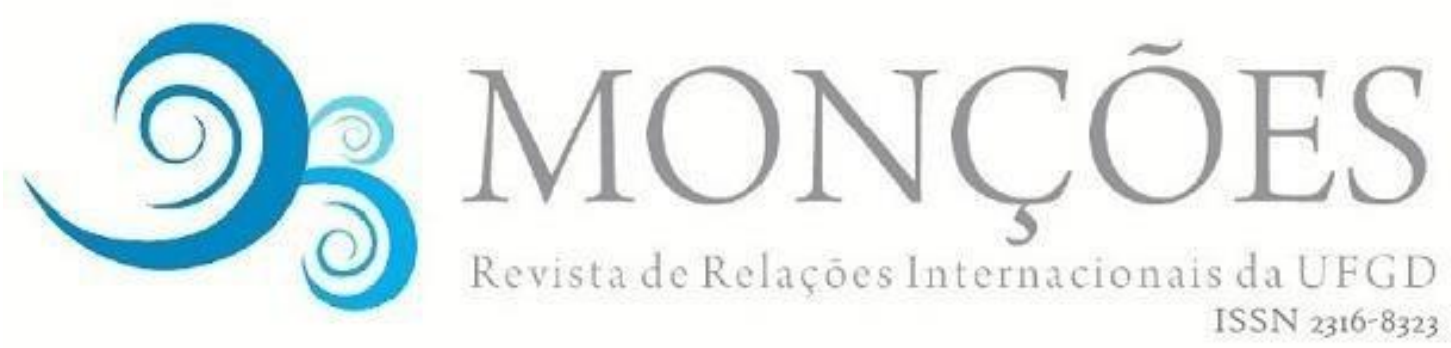

\title{
O FEDERALISMO E A NORMATIZAÇÃO DA ATUAÇÃO INTERNACIONAL DAS UNIDADES FEDERADAS: UMA ANÁLISE COMPARATIVA ENTRE ARGENTINA E BRASIL
}

\author{
ARTHUR PINHEIRO DE AZEVEDO BANZATTO \\ Professor Substituto dos cursos de Direito e Relações Internacionais da Universidade \\ Federal da Grande Dourados (UFGD). Mestre em Relações Internacionais pela \\ Universidade de Brasília (UnB) com bolsa da CAPES.
}

\begin{abstract}
DEBORAH SILVA DO MONTE
Doutoranda e Mestre em Relações Internacionais pela Pontifícia Universidade Católica de Minas Gerais (PUC/MG).
\end{abstract}

\begin{abstract}
RESUMO: Este artigo analisa comparativamente a normatização da inserção internacional das unidades federadas da Argentina e do Brasil e orienta-se pela seguinte pergunta de investigação: como a atuação internacional das unidades federadas se insere nos arranjos normativos $e$ institucionais da Argentina e do Brasil? Para respondê-la, abordam-se, primeiramente, as contribuições teóricas que informam as mudanças do federalismo ante aos fenômenos do sistema internacional contemporâneo, assinalando os efeitos sobre a normatização da atuação internacional dos governos subnacionais pelos Estados. A análise comparativa entre Argentina e Brasil demonstra que as variações em relação à normatização constitucional da matéria influenciam na produção de efeitos legais dos acordos internacionais firmados pelos governos subnacionais de ambos os países.
\end{abstract}

Palavras-Chave: Federalismo; Paradiplomacia; Constituição.

\section{FEDERALISM AND REGULATION OF THE INTERNATIONAL ENGAGEMENT OF THE FEDERAL UNITS: A COMPARATIVE ANALYSIS BETWEEN ARGENTINA AND BRAZIL.}

\begin{abstract}
This paper compares the regulation of the international engagement of the federal units and it is guided by the following inquiry: how is the international engagement of the federal units inserted into the normative and institutional arrangement of Argentina and Brazil? To answer it, we first approach the theoretical contributions about the changes in federalism towards some phenomena in the contemporary international system, emphasizing the effects on the regulation of the international engagement of the subnational governments by the State. The comparison between Argentina and Brazil shows that the variations regarding the constitutional treatment of the subject influence on the production of legal effects of the international acts firmed by subnational governments of both countries.
\end{abstract}

Keywords: Federalism; Paradiplomacy; Constitution. 


\section{INTRODUÇÃO}

Este artigo tem por objetivo analisar como a atuação internacional das unidades federadas tem sido normatizada por Estados Federais, especificamente Argentina e Brasil, e apresentar as principais consequências das variações institucionais em relação ao tratamento da matéria.

A escolha dos países analisados justifica-se pelas semelhanças e diferenças por eles compartilhadas: Dentre as similitudes, considera-se que: a) ambos possuem o Federalismo como forma de organização administrativoburocrática do Estado; b) os processos de redemocratização e liberalização econômica na Argentina e no Brasil aconteceram no mesmo período; e c) os dois Estados protagonizaram, no final da década de 1980 e início da década de 1990, a criação de um dos processos integrativos mais importantes da América do Sul (o Mercosul). Em relação às diferenças, considera-se: a) o processo de formação do Estado Federal (centrífugo/centrípeto); b) o tipo de federalismo (centralizado/ descentralizado); c) o tipo de unidade federada (federalismo dual ou em três níveis); e d) o grau de autonomia dos entes federados. Diante de tais características, busca-se responder à seguinte pergunta de investigação: como a atuação internacional das unidades federadas se insere nos arranjos normativos e institucionais de Argentina e Brasil?

$\mathrm{O}$ artigo organiza-se da seguinte forma: na primeira seção aborda-se a relação entre o federalismo, os fenômenos internacionais (como a interdependência, a globalização e a integração regional) e a normatização da atuação internacional dos governos subnacionais pelos Estados. Na segunda e terceira seções apresentam-se os aspectos normativos e institucionais que regulam a inserção internacional dos entes federados de Argentina e Brasil, respectivamente, seguidos pelas considerações finais - que organiza os resultados de maneira comparada. Os principais achados mostram que o tratamento constitucional da matéria, que varia entre os dois países, influencia na produção de efeitos legais dos acordos internacionais firmados pelas unidades federadas dos dois países em tela. 


\section{O FEDERALISMO DIANTE DAS MUDANÇAS DO SISTEMA INTERNACIONAL CONTEMPORÂNEO}

O federalismo surgiu com a Constituição dos Estados Unidos da América (1787), que transformou a até então confederação em uma federação, em que as partes tiveram que renunciar sua soberania e unir-se para construir um Estado Federal. A partir de então, o governo da União coexiste com os governos das unidades federadas, havendo duas categorias de ordenamento jurídico que se relacionam com, pelo menos, duas esferas distintas de poder: a federal e a estadual.

A partir da experiência estadunidense, outros Estados passaram a se organizar sob a forma federativa. O federalismo é apontado como o mais adequado para países dotados de grandes heterogeneidades e dimensões territoriais, sendo que sete dos oito maiores países do mundo, em extensão, são federações ${ }^{1}$. A autonomia político-administrativa concedida às unidades federadas - cujo grau varia conforme o país - favorece uma administração estatal mais harmônica, capaz de garantir uma distribuição de poder estável, legítima e democrática, ainda que nem sempre isso ocorra na prática.

Segundo Elazar (1987), o federalismo consiste na melhor combinação entre unidade e diversidade, com respeito à autonomia local. Nessa perspectiva, um arranjo federal é regulado por um pacto federativo, fundamentado pelo "[...] reconhecimento mútuo da integridade de cada parte e [pelo] esforço de favorecer uma unidade especial entre elas" (ELAZAR, 1987, p.5, tradução nossa) ${ }^{2}$.

Em relação às vantagens atribuídas ao federalismo, destaca-se a organização e a distribuição do poder ante aos eventuais benefícios econômicos. Ademais, trata-se da forma de organização estatal mais adequada para assegurar, em um regime político democrático cujo contexto social é de múltiplas clivagens a estabilidade política dos governos (KUGELMAS; BRANCO, 2005, p. 163). A busca por uma unidade nacional em tal contexto faz com que 0

\footnotetext{
${ }^{1}$ Rússia, Canadá, China, Estados Unidos, Brasil, Austrália e Argentina. A China, terceiro maior país em termos de extensão territorial, apesar de possuir alguns territórios autônomos, não constitui formalmente uma federação (LESSA, 2007).

2"“[...] based on a mutual recognition of the integrity of each partner and the attempt to foster a special unity among them".
} 
federalismo se guie pelos princípios da descentralização, da autonomia, da cooperação e do equilibrio entre os entes federados. Assim, a federação se apresenta como uma forma intermediária entre o Estado unitário, dotado de um poder altamente centralizado que concentra as decisões políticas, e a confederação, em que 0 ente central apenas coordena as unidades que 0 compõem, sendo mantida a soberania das partes.

Nas federações, a soberania pertence única e exclusivamente ao Estado Federal enquanto representante da nação, sendo suas unidades dotadas apenas de autonomia, isto é: um poder limitado que thes garante a capacidade de auto-organização, autogoverno, autoadministração e legislação própria com base no que é previsto pela Constituição de cada país.

Ademais, relaciona-se 0 federalismo à concepção pluralista de democracia, em que diferentes níveis de governo possuem poder político e administram seus respectivos territórios de maneira autônoma, ainda que existam interconexões entre as jurisdições (DUCHACEK, 1990). Lijphart (2003) associa o modelo consensual de democracia, que é caracterizado pela dispersão de poder e promoção do consenso entre os atores políticos, à vigência de um arranjo federativo. Destaca-se, contudo, que federalismo e democracia, ainda que aproximados e relacionados, são conceitos que se referem a diferentes categorias analíticas: o primeiro diz respeito à organização político-espacial do Estado e o segundo as instituições formais (regime político) de um país. De maneira combinada, eles abordam a organização da convivência de forma a desconcentrar poder e garantir a expressão política das minorias (ELAZAR, 1987; LIJPHART, 2003), e fundamentam-se em princípios democráticos (BONAVIDES, 1980, p. 117).

Apesar da distribuição de competências variar com a Constituição de cada Estado Federal, as atribuições em política externa e defesa permanecem restritas à União, segundo a teoria federalista clássica (DUCHACEK, 1970). O monopólio da União nesta matéria é considerado como uma característica fundamental de uma federação, fazendo com que ela se diferencie de uma confederação. Sendo assim, enquanto os membros de uma confederação são soberanos e, portanto, Estados em sentido pleno; os membros de uma federação são apenas autônomos, não possuindo capacidade para relacionar-se com 
outros Estados, já que este ato é uma prerrogativa da soberania plena (PRAZERES, 2004). Nesse sentido, destacam-se as contribuições de Duchacek (1970) ${ }^{3}$, que afirma que:

\begin{abstract}
Em uma federação é o governo nacional (federal) que mantém o controle final sobre os principais temas em política externa e a condução das relações internacionais pacíficas ou violentas. As atribuições do corpo diplomático e das forças armadas refletem as preocupações, interesses e objetivos da federação em vez daqueles das unidades subnacionais (DUCHACEK, 1970, p. 208, tradução nossa) ${ }^{4}$.
\end{abstract}

Ressalta-se que, no contexto relativo à passagem acima, Duchacek (1970) analisa os conceitos de política externa e relações internacionais sob a perspectiva restrita da high politics. Os temas econômicos e sociais, considerados como low politics, ainda estavam ofuscados por assuntos relativos à segurança e à defesa que dominavam a agenda internacional. Destaca-se, ainda, que o monopólio da União em assuntos internacionais não representa uma característica inexorável das federações, sujeitando-se, assim como outras competências políticas, às peculiaridades de cada Estado e também às transformações políticas, econômicas e sociais do sistema internacional (DUCHACEK, 1970, p. 6). Considera-se, assim, a necessidade das federações de constante aperfeiçoamento e adaptação diante das mudanças políticas, econômicas e sociais.

Entende-se que fenômenos internacionais - como a interdependência, a globalização e a integração regional - impulsionaram pressões contraditórias sobre as relações exteriores das Federações. Tal influência enfraquece, em alguma medida, a tradicional divisão entre o local, o nacional e o global. Sobre este novo contexto, Soldatos (1990), Duchacek (1990), Kincaid (1990) e Michelmann (1990) abordam a descentralização da política externa, de modo a garantir uma harmonia entre o engajamento internacional das unidades federadas e a política externa nacional.

\footnotetext{
${ }^{3}$ Esta opinião do autor foi reformada com o passar do tempo.

${ }^{4}$ In a federation, then, it is the national (federal) government in whose hands lie the ultimate control over the major issues in foreign policy and the conduct of peaceful or violent international relations. The tasks of both diplomatic service and the armed forces mirror the preoccupation, interests, and goals of the federal nation rather than those of the nation's territorial components .
} 
Nas Federações, coexistem interesses locais distintos, que não podem ser plenamente contemplados pelo governo central. Desta forma, os governos subnacionais, por estarem mais próximos dos cidadãos e mais permeáveis a manifestação de suas preferências, necessidades e problemas, estariam também mais aptos a atendê-los e resolvê-los.

Entende-se que, assim como o conceito de soberania estatal passou por um processo de reconfiguração, o monopólio do Estado na condução das relações internacionais também é relativizado diante da atuação dos governos não centrais nesta esfera (VIGEVANI, 1999, p. 47-48). Em um cenário internacional marcado pela interpenetração crescente entre questões domésticas e internacionais, questiona-se o monopólio das relações exteriores pelos governos centrais evidenciando, em certa medida, um relativo descompasso com as novas dinâmicas e atores do sistema internacional contemporâneo (MEDEIROS, 2007).

O fato de a maioria das Constituições Federais ainda estabelecer o monopólio dos governos centrais na condução da política externa encontra-se em consonância com o contexto em que estas Constituições foram promulgadas (Séculos XVIII e XIX), Entendia-se, predominantemente, que os Estados soberanos eram os únicos atores do sistema internacional, possuindo uma única voz legítima detentora do "interesse nacional": a do governo central (DUCHACEK, 1990).

Cedendo às pressões internas e externas, algumas federações como Argentina, Alemanha, Áustria, Bélgica e Suíça, relativizaram o monopólio do governo central na condução das relações internacionais. Rompeu-se, assim, com a premissa do federalismo clássico e promoveram-se novas concepções a respeito do Estado Federal e as diferentes possibilidades de inserção internacional de seus entes.

Destaca-se, nessa perspectiva, a ideia de um federalismo social, em que a autoridade política descentralizada é dotada de maiores competências inclusive internacionais - por ser compreendida como mais eficiente para a satisfação de demandas locais (SARAIVA, 2004). Considera-se, assim, que o federalismo contemporâneo, em contraposição ao federalismo tradicional, caminha no sentido de romper com o monopólio dos governos centrais nas 
relações internacionais, uma vez que este não se mostra mais eficiente e adequado à dinâmica do sistema internacional contemporâneo. Diante de uma atuação internacional cada vez maior dos governos não centrais através da paradiplomacia - isto é, uma inserção internacional autônoma e direta, sem a mediação do governo federal (DUCHACEK, 1990) - e da diplomacia federativa - uma inserção internacional indireta das unidades federadas na formulação da política externa através de mecanismos informais ou formais (DUCHACEK, 1990) -, é de grande importância que estas práticas sejam acompanhadas por marcos jurídicos e arranjos institucionais destinados a regulamentá-las, evitando o surgimento de conflitos políticos entre os diferentes níveis de governo (MAIA, 2012, p. 141).

A permissão jurídica para a atuação internacional dos governos não centrais varia em relação a cada país. De maneira geral, ela se apresenta sob a forma de dispositivos constitucionais que preveem possibilidades de ação externa de suas unidades federadas. Destaca-se, dentre elas, a capacidade para pactuar direitos e obrigações no âmbito internacional através de um acordo, convênio ou outro instrumento jurídico previsto legalmente.

A existência ou não de um marco jurídico com este objetivo implica em importantes consequências no âmbito da responsabilidade internacional, especialmente diante da hipótese de descumprimento dos acordos internacionais estabelecidos pelas unidades federadas. Embora este seja um tema ausente nos tratados de Direito Internacional Público, busca-se suprir esta lacuna através de análise da doutrina, da jurisprudência internacional e de documentos oficiais (BARROS, 2009). Nos casos que envolvem a responsabilização por descumprimento de acordo internacional celebrado por unidade federada autorizada legalmente a atuar no âmbito internacional, a doutrina apresenta algumas divergências.

Rezek (1984) defende que a responsabilidade recai sobre o Estado Federal enquanto garantidor dos compromissos celebrados por suas unidades federadas. Contrariamente, Crawford (2005) argumenta que a responsabilidade pertence à própria unidade federada que descumpriu o acordo pactuado, desde que a contraparte concorde com isto. Shaw (2003), por sua vez, reconhece a 
existência das duas possibilidades, alegando que cabe à legislação interna de cada Estado definir esta questão.

Ainda que no plano empírico os governos não centrais sejam reconhecidos como atores internacionais, este reconhecimento não foi plenamente garantido no plano jurídico. Por não possuírem personalidade jurídica internacional, as unidades federadas não são contempladas, segundo a doutrina tradicional do Direito Internacional Público, como signatárias de tratados internacionais (BRANCO, 2009).

Neste sentido, Azambuja (1997, p. 368) argumenta que, ao contrário do que ocorre nas confederações, a ausência de soberania por parte dos membros da federação faz com que esta possua natureza jurídica de "Estado simples" no âmbito do Direito Internacional Público. As competências - como o direito de representação ativa e passiva e o direito de celebrar tratados - seriam restritos à União enquanto único ente soberano. Accioly (1986, p. 18), semelhantemente, defende que as competências de representação internacional e de defesa pertencem exclusivamente ao Governo Federal, característica presente em sua própria definição conceitual de Estado Federal.

Considerando os tratados internacionais ${ }^{5}$ como os principais mecanismos de criação de direitos, deveres e compromissos entre atores internacionais, a ausência de personalidade jurídica resulta em severas consequências dentro de um contexto internacional cada vez mais interdependente e globalizado, marcado pela atuação de atores não estatais na política internacional.

O Projeto da Convenção de Viena, de 1969, apresentava, em seu art. 5ํㅡ, uma disposição sobre a possibilidade de estados-membros de federações concluírem tratados internacionais, desde que esta prática fosse autorizada por sua respectiva Constituição. Por razões diversas, contudo, esta norma não prevaleceu no texto final da Convenção aprovada.

Mesmo assim, o poder conferido ao Estado soberano para determinar, no seu plano jurídico interno, quais entes possuem capacidade jurídica para

\footnotetext{
${ }^{5}$ A Convenção de Viena sobre o Direito dos Tratados entre Estados e Organizações Internacionais ou entre Organizações Internacionais de $1986^{5}$ estabelece em seu art. $2^{\circ}$ que um tratado é um "acordo internacional regido pelo direito internacional e celebrado por escrito entre um ou vários Estados e uma ou várias organizações internacionais ou entre organizações internacionais".
} 
celebrar tratados permite interpretações de que é possível que as unidades federadas o façam sem violar o direito internacional (REZEK, 2011; PAIKIN, 2010; VARELA, 2010). Concebe-se, assim, que a responsabilidade da União como garantidora do compromisso firmado por sua unidade federada no âmbito do Direito Internacional Público é vista como análoga a responsabilidade dos representantes dos agentes que possuem capacidade contratual relativa no âmbito do Direito Civil (REZEK, 1984). Uma análise posterior indica que o respeito ao princípio do consentimento do Estado soberano e a existência de algum tipo de previsão legal no ordenamento jurídico interno, possibilitam que os governos não centrais celebrem compromissos internacionais dotados de validade jurídica. Caso estes dois requisitos não sejam cumpridos, estes compromissos representariam mera expressão de intenções sem vinculação legal, criando direitos e deveres de caráter apenas moral (LESSA, 2007).

Em suma, entende-se que, mesmo não estando prevista expressamente pelo Direito Internacional Público, a formalização de compromissos internacionais assumidos por governos não centrais tampouco é vedada a priori, cabendo ao Estado nacional, enquanto ente soberano, atribuir ou não este tipo de competência.

A análise de como esta questão aparece em algumas federações - no caso deste artigo, Argentina e Brasil - demonstra que os Estados concedem diferentes graus de autonomia para suas unidades federadas se envolverem diretamente em assuntos internacionais e de legitimidade para eles participarem dos processos decisórios em política externa. Seitenfus e Ventura (2006, p. 39) defendem que a restrição jurídica à atuação dos governos não centrais em tal matéria, apesar de não estar em consonância com o contexto internacional contemporâneo, ainda prevalece na ampla maioria das federações, havendo poucas exceções a esta regra 6 . Diante desta situação, o autor sugere que as federações adotem o princípio da subsidiariedade, de modo que a União atue apenas nos domínios em que ela estiver em melhores condições que as autoridades regionais.

\footnotetext{
${ }^{6} \mathrm{O}$ autor cita como exceção apenas os casos da Áustria, da Alemanha e da Bélgica, apesar de a literatura sobre o tema apontar outros países cuja Constituição Federal autoriza algum tipo de atuação internacional por parte de suas unidades federadas, como a Argentina e a Suíça.
} 
Segundo Lessa (2007, p. 82-83), as diferentes formas pelas quais os governos não centrais atuam no plano internacional, inclusive através da celebração de acordos, não representa uma violação à soberania nacional. Nos dois países analisados comparativamente a seguir (Brasil e Argentina), a atuação internacional das unidades federadas se restringe a questões socioeconômicas - consideradas como de low politics - que afetam diretamente seus interesses locais, resguardando assim a capacidade dos seus governos centrais em conduzirem suas políticas externas. Não se considera, portanto, uma substituição ou contestação da política externa e da diplomacia tradicional desenvolvida na esfera interestatal, mas sim em iniciativas pontuais que buscam complementá-la (IGLESIAS, 2008; MAIA, 2015).

\title{
2. A NORMATIZAÇÃO DA ATUAÇÃO INTERNACIONAL DAS UNIDADES FEDERADAS ARGENTINAS.
}

O principal avanço promovido pela reforma constitucional argentina (1994) ${ }^{7}$, em relação à normatização da atuação internacional das unidades federadas da Argentina foi a inclusão do art. 124 com a seguinte redação:

\begin{abstract}
Artículo 1240.- Las provincias podrán crear regiones para el desarrollo económico y social y establecer órganos con facultades para el cumplimiento de sus fines y podrán también celebrar convenios internacionales en tanto no sean incompatibles con la política exterior de la Nación y no afecten las facultades delegadas al Gobierno federal o el crédito publico de la Nación; con conocimiento del Congreso Nacional. La ciudad de Buenos Aires tendrá el régimen que se establezca a tal efecto (ARGENTINA, 1994).
\end{abstract}

Ao prever expressamente a possibilidade das províncias argentinas celebrarem convênios internacionais, o referido dispositivo introduziu um importante marco jurídico para a paradiplomacia, tornando a Argentina o único país da América do Sul (e um dos únicos do mundo) a ter normatizado

\footnotetext{
7 A trajetória em direção à democracia na Argentina foi marcada por retrocessos - períodos de ditaduras militares e civis - e crises políticas. O último golpe contra o governo civil ocorreu1976. No ano de 1983 foi eleito Raúl Alfonsín, primeiro presidente civil desta etapa democrática da Argentina, pela Unión Cívica Radical Diferentemente do caso brasileiro - em que se promulgou uma nova constituição - a Argentina realizou, em 1994, uma reforma sistemática da Constituição de 1853, marcando o atual período democrático.
} 
constitucionalmente esta prática.

Entende-se que etse avanço institucional aumentou e aperfeiçoou as práticas paradiplomáticas e fomentaram 0 desenvolvimento regional e a cooperação descentralizada na Argentina (BRANCO, 209, p. 69; BARROS, 2009, p. 111). Mariano e Mariano (2002) apontam a reforma constitucional argentina como uma importante forma de contrabalancear a vulnerabilidade dos governos não centrais diante dos processos de integração regional e das dificuldades de interlocução com o governo federal para se compensar eventuais prejuízos. Paikin (2010), por sua vez, destaca que as competências atribuídas às províncias pelo art. 124 da Constituição Argentina obriga as partes signatárias da mesma forma que os tratados internacionais celebrados por Estados Nacionais, ainda que haja divergências doutrinárias com relação a quem recai a responsabilidade internacional nestas situações.

Considerando a discussão existente no âmbito do Direito Internacional Público, Varela (2010) e Dalla Via (1999) defendem que a responsabilidade internacional recai sobre o Estado Federal argentino, uma vez que as províncias não são regidas pelo Direito Internacional e, portanto, não possuem personalidade jurídica internacional.

Apesar de garantir os interesses provinciais, o art. 124 resguardou-se para que a prática de celebrar tais convênios internacionais não fosse abusiva, garantindo, também, os interesses do governo central ao impor requisitos como: (i) a não incompatibilidade com a política externa da Nação; (ii) a não afetação das faculdades delegadas ao governo federal; (iii) a não afetação ao crédito público nacional; e (iv) a necessidade de conhecimento do Congresso Nacional.

$O$ primeiro requisito (i) se baseia na premissa de que a atuação internacional das províncias não deve invadir a competência do governo federal. Muito embora as províncias tenham legitimidade para celebrar convênios internacionais, isto não quer dizer que elas possam desenvolver uma política externa, no sentido estrito do termo (VARELA, 2010; CARBAJALES; GASOL, 2008). Entende-se que estes convênios devem ser limitados a assuntos econômicos e sociais como empréstimos internacionais, financiamento de obras e transferência de tecnologia (EKMEKDJIAN,1999). Com relação os critérios que determinam se um convênio é ou não compatível com a política externa 
argentina, Pakin (2010) aponta a existência de uma lacuna jurídica, sendo necessária uma norma regulamentadora do referido artigo de modo a definir indicadores mais precisos sobre esta questão da compatibilidade.

O segundo requisito (ii) relaciona-se diretamente com o anterior, ao considerar que os poderes delegados exclusivamente ao governo federal se encontram previstos nos arts. 75, 99, 100 e 116 da Constituição (CARBAJALES; GASOL, 2008). O art. 125 complementa este requisito, estabelecendo as matérias que podem ser pactuadas pelas províncias, como se demonstra a seguir:

\footnotetext{
Artículo 125.- Las provincias pueden celebrar tratados parcialespara fines de administración de justicia, de intereses económicos y trabajos de utilidad común, con conocimiento del Congreso Federal; y promover su industria, la inmigración, la construcción de ferrocarriles y canales navegables, la colonización de tierras de propiedad provincial, la introducción y establecimiento de nuevas industrias, la importación de capitales extranjeros y la exploración de sus ríos, por leyes protectoras de estos fines, y con sus recursos propios (ARGENTINA, 1994).
}

O terceiro requisito (iii), por fim, significa, na visão de que Ekmekdjian (1999), que os convênios financeiros celebrados pelas províncias com contrapartes estrangeiras não devem comprometer o governo federal como fiador ou avalista. Por outro lado, Paikin (2010, p. 44) alega que o papel de avalista do Estado se faz necessário diante das normas de Direito Internacional.

$\mathrm{Na}$ prática, o governo federal exerce o papel de avalista nos casos de financiamentos ou empréstimos contratados pelas províncias. No entanto, isto não ocorre de forma automática, uma vez que existe a necessidade de aprovação prévia destas operações. Esta condição faz com que o Governo Federal regulamente este procedimento através de leis federais e agências nacionais, impondo requisitos adicionais e limites ao endividamento provincial que variam diante das circunstâncias políticas e econômicas de cada contexto (IGLESIAS, 2008).

Com relação aos empréstimos diretos contratados pelas províncias argentinas junto a organismos financeiros internacionais, Iglesias (2008) argumenta que é o Estado que se obriga como avalista na medida em são impostos regulações e procedimentos necessários à contratação destes empréstimos. Por este motivo, a autora afirma que esta prática não contradiz o 
requisito estabelecido no art. 124. Complementarmente, Carbajales e Gasol (2008, p. 62-63) defendem que a função de avalista do governo federal relacionase diretamente com o fato de ele possuir responsabilidade internacional sobre os atos cometidos por suas províncias, a exemplo do que ocorreria em casos de inadimplência.

Finalmente, o último requisito (conhecimento do Congresso Nacional) é o mais polêmico, havendo divergências sobre o significado exato do termo "conhecimento". Para Campos (1997), Sola (1997) e Dalla Via (2004), ele representaria a necessidade de aprovação, possibilitando ao Congresso exercer um controle preventivo sobre os convênios. Outros autores (EKMEKDJIAN, 1999; DROMI E MENEM, 1994), em contrapartida, defendem que o conhecimento implicaria em uma mera notificação, de modo a resguardar a autonomia das províncias e evitar que elas fiquem em uma situação de dependência do Congresso. Segundo Paikin (2010, p. 43) e Lessa (2007, p. 44), a jurisprudência argentina adota a ideia de que o conhecimento não implica na necessidade de aprovação por parte do Congresso, havendo apenas a exigência de que ele seja notificado pela província, quando esta celebra algum convênio internacional.

Outra questão aborda a natureza jurídica destes convênios internacionais, isto é: se eles se equiparam ou não aos tratados internacionais previstos pela Convenção de Viena sobre o Direito dos Tratados. Tal impasse suscita algumas divergências doutrinárias: de um lado, autores como Lavie et al (2009) e Varela (2010, p. 15), afirmam que a escolha do termo "convênio" para descrever os acordos internacionais celebrados pelas províncias argentinas foi proposital, com o intuito de destacar o seu alcance jurídico mais limitado em relação aos tratados celebrados pelo governo central.

De outro lado, Sánchez (2004) e Dalla Via (2004) defendem que a diferença entre tratado e convênio é apenas terminológica, não havendo elementos que os distinguem no âmbito do Direito Constitucional argentino ou do Direito Internacional Público. Ao analisar a questão específica dos convênios celebrados pelas províncias argentinas, Sanchéz (2004) faz uma ressalva, reconhecendo que estes não possuem os mesmos atributos dos tratados celebrados pelo governo central argentino. Dentre as consequências práticas 
desta distinção, ressalta-se que, ao contrário dos tratados, os convênios não possuem hierarquia superior às leis nacionais argentinas ${ }^{8}$.

Em suma, Dalla Via (2004), Carbajales e Gasol (2008), Varela (2010) e Paikin (2010) destacam a necessidade de regulamentação do art. 124 para suprir as lacunas e as divergências doutrinárias apresentadas. Feitas todas estas considerações, entende-se que o art. 124 da Constituição Argentina representa um importante avanço ao legitimar juridicamente uma atuação externa formal por parte de suas províncias, procedimento que até hoje não foi feito no Brasil. Os requisitos estabelecidos pelo próprio artigo, longe de representarem uma limitação substancial à autonomia das províncias, garantem a soberania nacional e o pacto federativo, demonstrando que é possível normatizar a paradiplomacia ao mesmo tempo em que se preserva a integridade da política externa tradicional, de competência do governo central. Ainda assim, destaca-se que tal instrumento não garante plena segurança jurídica aos convênios deste tipo natureza, evidenciada pelas divergências doutrinárias a respeito de sua natureza, alcance, responsabilidade internacional e da forma com que seus requisitos devem ser interpretados. Tais incongruências apontam para a necessidade de regulamentação do referido artigo, de modo a estabelecer critérios mais objetivos a respeito dos elementos apontados, já que a sua redação atual se mostra vaga.

\section{A NORMATIZAÇÃO DA ATUAÇÃO INTERNACIONAL DAS UNIDADES FEDERADAS BRASILEIRAS.}

A Constituição Federal de 1988 estabelece a forma federativa de Estado já em seu primeiro artigo ${ }^{9}$, que é complementado pelo Art. $18^{10}$. Ao acrescentar os municípios como uma nova espécie de entes federados autônomos aos já

\footnotetext{
${ }^{8}$ Segundo o art. 99, inc. 11 da Constituição, a celebração de tratados internacionais celebrados com nações estrangeiras ou organizações internacionais é de competência do Presidente, cabendo ao Congresso aproválos ou rejeitá-los (art. 75, inc. 22). Uma vez aprovados estes tratados passam a ter hierarquia superior às leis, o que não ocorre com os convênios internacionais celebrados pelas províncias argentinas.

9 “A República Federativa do Brasil, formada pela união indis solúveldos Estados e Municípios e do Dis trito Federal...",

10 “A organização político-administrativa da República Federativa do Brasil compreende a União, os Estados, o Distrito Federal e os Municípios, todos autônomos, nos termos desta Constituição".
} 
existentes entes federados típicos (União e estados-membros), a Constituição brasileira apresenta uma inovação ao federalismo clássico dualista, que possui apenas dois níveis de poder político: o central e o regional. Desta forma, o federalismo brasileiro é composto por três esferas de poder (União, estadosmembros e municípios) ao invés de apenas duas como é o padrão das federações ${ }^{11}$. Além dos municípios, a Constituição de 1988 instituiu, também, o Distrito Federal ${ }^{12}$, um ente federado sui generis que possui competências tanto municipais quanto estaduais. O caráter autônomo de cada ente da federação significa que não há hierarquia entre eles, havendo apenas uma repartição de competências que são previstas ao longo do texto constitucional.

Outras características comuns à maioria das federações são previstas constitucionalmente como a inexistência do direito de secessão; a autoorganização dos Estados-membros ${ }^{13}$; a existência de um órgão representativo dos Estados-membros (Senado Federal, SF) ${ }^{14}$; e a indissolubilidade do vínculo federativo ${ }^{15}$. Assim como na Constituição Argentina de 1994, nossa Carta Magna também estabelece o princípio da subsidiariedade em seu art. $25^{16}$. Apesar de a análise deste artigo indicar, a princípio, um alto grau de descentralização por parte do federalismo brasileiro, as competências exclusivas (art. 21) e privativas (art. 22) ${ }^{17}$ da União são tantas que o poder residual dos estados torna-se bastante limitado. Costa (2005) afirma que a União concentra um total de 54 competências privativas. A título de comparação, Patroni (2005) aponta que na Argentina este número é de apenas 28. Desta forma, alguns autores classificam o federalismo brasileiro como tradicional e assimétrico, em que o governo central

11 A Bélgica também possui um pacto federativo tripartite.

12 Art. 34. A União não intervirá nos Estados nem no Distrito Federal, exceto para: I - manter a integridade nacional; Segundo o art. 32, $\S 1^{\circ}$ : "Ao Distrito Federal são atribuídas as competências legislativas reservadas aos Estados e Municípios".

13 Art. 25. Os Estados organizam-se e regem-se pelas Constituições e leis que adotarem, observados os princípios desta Constituição.

14 Art. 46. O Senado Federal compõe-se de representantes dos Estados e do Distrito Federal, eleitos segundo o princípio majoritário.

15 Art. $60, \S 4^{\circ}$ - Não será objeto de deliberação a proposta de emenda tendente a abolir: I - a forma federativa de Estado;

16 Art. 25. Os Estados organizam-se e regem-se pelas Constituições e leis que adotarem, observados os princípios desta Constituição. $§ 1^{\circ}$ São reservadas aos Estados as competências que não thes sejam vedadas por esta Constituição.

17 As competências exclusivas do art. 21 são aquelas que não podem ser delegadas a nenhum outro ente da federação, cabendo somente à União executá-las, ao passo que as competências privativas do art. 22 podem ser delegadas aos estados e municípios (LENZA, 2009). 
concentra vários poderes e prerrogativas (BASTOS, 1999; LESSA, 2007; BRANCO, 2009).

No tocante as competências internacionais, destaca-se que, enquanto os entes da federação são autônomos entre si, a República Federativa do Brasil é soberana no plano internacional, sendo representada pela União em suas relações internacionais. Isso faz com que a União possua uma espécie de "dupla personalidade", que atua internamente como uma pessoa jurídica de direito público - dotada de autonomia financeira, administrativa e política - e que atua internacionalmente em nome de toda a federação enquanto representante da República Federativa do Brasil (LENZA, 2009, p. 300).

Ao contrário da Argentina, onde as ações externas dos governos não centrais são constitucionalmente reconhecidas, a paradiplomacia no Brasil não possui previsão constitucional expressa, sendo que a Constituição de 1988 atribui somente à União a competência para relacionar-se com Estados estrangeiros ${ }^{18}$. Desta forma, compete ao Presidente da República acreditar seus representantes diplomáticos e celebrar os tratados, convenções e atos internacionais $^{19}$, que deverão ser referendados no plano interno pelo Congresso Nacional20. A leitura do texto constitucional nos permite apontar que, embora a soberania nacional pertença à República Federativa do Brasil, formada pela União, Estados, Distrito Federal de Municípios ${ }^{21}$, é a União o ente responsável por representá-la no plano externo.

Tanto a orientação majoritária da doutrina constitucionalista quanto 0 Itamaraty, através de sua Consultoria Jurídica, defendem que não compete às unidades federativas brasileiras celebrarem acordos que acarretem compromissos no plano internacional, pois tal ato é de competência exclusiva da União, que é quem possui personalidade jurídica internacional (PRAZERES,

18 Art. 21. Compete à União: I - manter relações com Estados estrangeiros e participar de organizações internacionais;

19 Art. 84. Compete privativamente ao Presidente da República: [...]; VII - manter relações com Estados estrangeiros e acreditar seus representantes diplomáticos; VIII - celebrar tratados, convenções e atos internacionais, sujeitos a referendo do Congresso Nacional; [...].

20 Art. 49. É da competência exclusiva do Congresso Nacional: I - resolver definitivamente sobre tratados, acordos ou atos internacionais que acarretem encargos ou compromis sos gravosos ao patrimônio nacional; [...].

21 Art. 18. A organização político-administrativa da República Federativa do Brasil compreende a União, os Estados, o Distrito Federal e os Municípios, todos autônomos, nos termos desta Constituição. 
2004). Destaca-se, nesta perspectiva, o Parecer MRE/CJ n. 13/1999, que afirma que Estados, Municípios e o Distrito Federal não possuem nenhuma competência para a condução das relações exteriores ${ }^{22}$.

A única possibilidade de atuação internacional dada pela Constituição aos estados e municípios consiste na capacidade de firmar acordos financeiros externos, desde que com o aval do Senado Federal, conforme art. 52, inc. $\mathrm{V}^{23}$. Tal situação se restringe a contratos de empréstimo junto a organismos financeiros internacionais, sendo a autorização do Senado um elemento imprescindível para a legitimação e validade destes contratos. Em relação a esta matéria, Rodrigues (2008) afirma que desde os anos 1990 os estados e municípios brasileiros mantêm negociações diretas com organismos econômicos internacionais, a exemplo do Banco Internacional para Reconstrução e Desenvolvimento (BIRD), do Banco Interamericano de Desenvolvimento (BID) e do Programa das Nações Unidas para o Desenvolvimento (PNUD).

Desta forma, considera-se que mesmo diante da ausência de uma norma capaz de legitimar a atuação internacional formal das unidades federadas brasileiras em sua totalidade, a paradiplomacia financeira encontra-se inserida dentro de um marco jurídico. Além de estar prevista constitucionalmente, esta modalidade de paradiplomacia ganha elevada importância a partir do aumento das responsabilidades das unidades federadas no atendimento às demandas socioeconômicas de suas populações.

Retoma-se que a redefinição do pacto federativo brasileiro, apesar de representar um grande avanço com relação ao período da ditatorial, não consolidou um federalismo plenamente descentralizado no Brasil. Deste modo, o aumento das responsabilidades dos estados e municípios em relação à implementação de políticas públicas não foi acompanhado da descentralização tributária adequada que garantisse os recursos financeiros necessários para tal. Diante de certas limitações orçamentárias, os estados e municípios passaram a buscar alternativas para cumprir com suas novas responsabilidades, recorrendo

\footnotetext{
22 [...] a ordem constitucional pátria é categórica ao conceder expressamente à União competência para conduzir as relações exteriores. Não faz nenhuma concessão às unidades federadas, sejam Estados, Municípios ou o Distrito Federal. (Parecer MRE/CJ n. 13/1999).

${ }^{23}$ Art. 52. Compete privativamente ao Senado Federal: [...]; V - autorizar operações externas de natureza financeira, de interesse da União, dos Estados, do Distrito Federal, dos Territórios e dos Municípios; [...].
} 
muitas vezes ao cenário internacional (BARROS, 2009).

Neste contexto, a paradiplomacia financeira desponta como importante iniciativa para corrigir o descompasso existente entre responsabilidades e recursos. Através da negociação e contratação direta de recursos externos oferecidos por organismos internacionais, oficiais ou privados, e/ou governamentais estrangeiros, as unidades federadas brasileiras passam a obter as seguintes novas possibilidades: a) financiar projetos de investimento público; b) obter recursos a custos menores e com prazos maiores de amortização que no mercado interno; c) complementar seu orçamento restrito; d) ter acesso a melhores práticas para a formulação de políticas e a gestão de projetos a partir da cooperação técnica e financeira dos organismos internacionais. Tais ações permitem que os governos subnacionais do Brasil se projetem no cenário internacional como um parceiro credível e confiável, atraindo investimentos privados estrangeiros (MAIA, 2012).

A intervenção do governo federal através do controle do endividamento subnacional realizado pelo Senado deve-se ao fato de os estados e municípios não possuírem soberania nem personalidade jurídica internacional, necessitando da atuação da União enquanto garantidora contra eventual risco de inadimplência junto ao credor internacional. Ou seja, a União exerce nestes casos o papel de fiadora, respondendo subsidiariamente pelo exato cumprimento das obrigações assumidas por sua unidade federada (REZEK, 2011).

Mesmo com a ingerência do governo federal através da regulamentação, do controle, do monitoramento e da aprovação destes empréstimos, há uma fase prévia ao processo formal em que os estados e municípios candidatos a mutuário negociam diretamente com o agente financiador os termos do acordo a ser celebrado (MAIA, 2012).

Observa-se, assim, que mesmo não sendo uma forma completamente autônoma de atuação externa por parte dos governos não centrais brasileiros, a paradiplomacia financeira representa uma importante plataforma de atuação internacional destes atores. Além dos acordos celebrados nesta esfera, o Ministério das Relações Exteriores propõe a celebração de ajustes 
complementares $^{24}$ entre as partes de um tratado internacional em vigor, que poderiam complementar a matéria de interesse de uma unidade federada e até mesmo indicá-la como entidade executora do referido ajuste (PRAZERES, 2004). Neste sentido, destaca-se a crescente quantidade de convênios de cooperação técnica entre municípios e estados brasileiros e contrapartes estatais estrangeiras, com o objetivo de implementar políticas públicas com base em tratados ou documentos internacionais (RODRIGUES, 2008). Segundo Soldatos (1990, p. 38), no entanto, a atuação internacional das unidades federadas brasileiras com base nestes acordos-quadro ${ }^{25}$, também chamados de acordos "guarda-chuva" (umbrella agreement), não se enquadraria dentro da paradiplomacia em sentido estrito, estando mais vinculada à diplomacia federativa pelo fato de implicar em uma ação coordenada pelo Governo Federal.

No âmbito das relações bilaterais, destacam-se três importantes instrumentos normativos que permitiram a atuação internacional das unidades federadas brasileiras. O primeiro deles foi o Protocolo Regional Fronteiriço n. 23 do Programa de Integração e Cooperação Econômica entre Brasil e Argentina (1988) que estabeleceu os objetivos para uma maior integração física, econômica e cultural entre os estados brasileiros do Rio Grande do Sul, de Santa Catarina e do Paraná e as províncias argentinas de Corrientes, Chaco, Entre Rios, Formosa, Misiones e Santa Fé.

Posteriormente, o Brasil celebrou outros dois importantes Protocolos Adicionais sobre Cooperação Descentralizada com base em Acordos-Quadro de Cooperação Bilateral com a Itália $(2007)^{26}$ e com a França $(2008)^{27}$, ressaltando

\footnotetext{
24 “Ato que normatiza a execução de outro, anterior - em muitos casos, um Acordo-Quadro ou um Acordo Básico. Detalha áreas de entendimento específicas e formas de implementação. Este formato tem sido particularmente utilizado para dar forma às crescentes atividades de cooperação técnica no âmbito da Agência Brasileira de Cooperação (ABC). Tendo em vista sua evolução para um caráter cada vez mais técnico-administrativo - no sentido de definir a produção de projetos de cooperação - e menos jurídicoformal, os Ajustes Complementares tendem cada vez mais a assumir a forma de Programas Executivos" (MRE, 2010, p. 7).

25 "Também conhecidos como "guarda-chuva", estabelecem marco geral de cooperação, devendo ser complementados por instrumentos posteriores, como os Ajustes Complementares ou os Programas Executivos, que implementam seus amplos dispositivos no plano concreto. Esses tipos de acordos definem o arcabouço institucional que passará a orientar a execução da cooperação” (MRE, 2010, p. 7).

26 Disponível em <http://www.planalto.gov.br/ccivil_03/_Ato2007-2010/2010/Decreto/D7400.ht m>. Acesso em 19 de agosto de 2015.

27 Disponível em: <http://www2.camara.leg.br/legin/fed/decleg/2011/decretolegislativo-293-22 setembro-2011-611497-publicacaooriginal-133683-pl.html >. Acesso em 19 de agosto de 2015.
} 
a importância e as vantagens desta modalidade de cooperação. Nestes acordos, as partes reconhecem aos respectivos governos não centrais a possibilidade de estabelecer entre si acordos de cooperação restritos às matérias cuja competência Ihes seja atribuída pela legislação interna em questões de interesse local e regional, resguardada as competências constitucionais do governo central.

Além de contemplar os interesses estaduais e municipais nos assuntos externos, esta forma de atuação é desenvolvida com a assistência do governo federal e dentro dos parâmetros constitucionais, o que garante a formalidade dos instrumentos normativos celebrados. Apesar de constituir uma importante solução para superar a informalidade da ampla maioria das iniciativas internacionais desenvolvidas pelos estados e municípios brasileiros, Lessa (2007) faz a ressalva de que a necessidade de um acordo prévio celebrado no âmbito interestatal implica em uma ingerência muitas vezes desnecessária por parte da União em temas vinculados a interesses e competências tipicamente estaduais e/ou municipais. Semelhantemente, Barros (2009) critica esta ingerência da União, uma vez que nestes casos ela é responsável por estabelecer todos os termos, sujeitos, diretrizes e limites dos acordos a serem celebrados pelas unidades federadas, restringindo substancialmente sua autonomia.

Ao realizar um importante estudo que mapeia a inserção internacional dos governos não centrais brasileiros, Lessa (2007) identifica as seguintes características: (i) a não extrapolação dos temas de competência estadual e municipal; (ii) a duplicidade de ação entre o Estado brasileiro e suas unidades federadas; (iii) a presunção de legalidade; e (iv) e o caráter informal dos atos.

A não extrapolação dos temas de competência estadual e municipal (i) significa que as unidades federadas brasileiras, ao celebrarem atos internacionais, não costumam invadir temas que a Constituição estabelece como de competência exclusiva (art. 21) ou privativa (art. 22) da União. Em geral, os atos celebrados versam sobre: cooperação e intercâmbio comercial, tecnológico e cultural; turismo; investimentos; meio ambiente; compartilhamento de informações; educação e capacitação profissional. Mesmo nos raros casos de não observância destas competências, não foram registrados desdobramentos 
envolvendo a implementação do ato, nem conflitos de qualquer espécie com o governo federal, uma vez que tais atos não chegaram nem sequer a produzir efeitos legais (LESSA, 2007).

A duplicidade de ação entre o Estado brasileiro e suas unidades federadas (ii) diz respeito à ampla convergência entre os temas de interesse nacional e estadual/municipal. Observou-se que muitos objetivos e áreas de interesse dos atos celebrados por uma unidade federada com algum ente de outro país eram bastante similares àqueles celebrados pelo governo central brasileiro com o governo central do mesmo país. Diante desta situação, Lessa (2007) aponta que grande parte destes atos poderia ter sido formalizada junto aos acordos feitos pela União sob a forma de um ato executivo que seria negociado pelas unidades federadas, mas firmado pelo governo federal, que as designaria como entidades executoras. Isso não ocorre devido ao fato de o governo central não dispor de meios para divulgar sistematicamente as informações a respeito dos acordos que ele possui com outros Estados e das formalidades necessárias para o estabelecimento de parcerias internacionais entre unidades federadas.

A presunção da legalidade implica na falsa percepção, por parte de agentes públicos que atuam na área da paradiplomacia, de que os atos internacionais celebrados por eles se resumem a um ato de vontade, não necessitando de uma moldura jurídica que os sustente. Partindo da equivocada ideia de que a simples assinatura é suficiente para gerar efeitos legais, os atos celebrados costumam conferir poderes e faculdades às partes como se estivessem realizando um contrato no âmbito do Direito Privado. Alguns atos chegam ainda a conter dispositivos de "solução de controvérsias", estabelecendo a legislação e o foro que serão utilizados em caso de descumprimento dos compromissos pactuados. Na prática, no entanto, as controvérsias advindas destes atos nem sequer chegariam a ser reconhecidas por um tribunal, seja ele nacional ou internacional.

Retoma-se que a ausência de um marco jurídico amplo faz com que os acordos internacionais celebrados pelas unidades federadas brasileiras não produzam efeitos jurídicos capazes de gerar direitos e obrigações entre as partes. O caráter informal destes acordos provoca algumas consequências que 
são apontadas por Lessa (2007, p. 126) como "carências". Dentre elas destacamos as seguintes:

1) Dispersão de objetivos: Ao invés de apresentar um objetivo concreto, muitos acordos buscam abranger o maior número de temas e ações possíveis, o que resulta na perda de foco e na dificuldade em executá-los de forma eficaz; 2) Personalismo:O caráter informal dos acordos faz com que sua execução dependa quase que exclusivamente do compromisso pessoal de um líder local; 3) Descontinuidade: Diretamente associada ao personalismo, a descontinuidade na execução dos acordos ocorre porque eles carecem de institucionalidade e, portanto, dependem da vontade política das partes para serem cumpridos. As constantes mudanças de governo fazem com que os novos políticos não tenham interesse em cumprir com os acordos firmados pela gestão anterior, dificultando o estabelecimento de parcerias duradouras.

Diante das limitações legais e institucionais existentes, é cada vez mais forte a demanda das unidades federadas brasileiras por uma atuação internacional mais formalizada. Percebe-se um forte descompasso entre o plano normativo, estabelecido pela nossa Constituição Federal, e o plano empírico, no qual as unidades federadas desempenham uma série de iniciativas externas. Este cenário faz com que autores como Prazeres (2004), Kugelmas e Branco (2005), Lessa (2007), Rodrigues (2008), Branco (2009) e Barros (2009) defendam algum tipo de reforma constitucional que normatize 0 instituto da paradiplomacia no Brasil, viabilizando a atuação externa direta dos governos subestatais pátrios, a exemplo do que foi feito em países como a Alemanha, a Bélgica, a Áustria e a Argentina.

Buscando proporcionar mais autonomia à inserção internacional dos governos não centrais brasileiros, bem como formalizar suas ações no plano externo, uma Proposta de Emenda Constitucional (PEC) (n. 475/05) 28 foi apresentada ao Congresso pelo Deputado Federal André Costa (PDT, RJ), pela qual se acrescentaria um parágrafo ao art. 23 da Constituição o seguinte texto: "Os Estados, Distrito Federal e Municípios, no âmbito de suas respectivas

\footnotetext{
${ }^{28}$ Documento disponível em: <http://www.camara.gov.br/proposicoes Web/fichadetramitacao?idProposicao=305376>. Acesso em $7 \mathrm{de}$ agosto de 2014.
} 
competências, poderão promover atos e celebrar acordos ou convênios com entes de subnacionais estrangeiros, mediante prévia autorização da União, observado o artigo 49, e na forma da lei".

André Costa - que é também diplomata de carreira - justificou a importância da PEC alegando que o Brasil é uma federação trina que contém, além do Distrito Federal, 26 Estados e mais de 5.000 Municípios autônomos que interagem globalmente através de diversas iniciativas como viagens internacionais de prefeitos e governadores, celebração de acordos de cooperação, estabelecimento de parcerias em diversas áreas, entre outras. Ademais, o congressista defendeu que tal alteração constitucional promoveria o desenvolvimento econômico e comercial das unidades federadas, como também fortaleceria o federalismo, diminuiria as desigualdades regionais, constituindo, assim, e constituir um avanço na própria consolidação da democracia brasileira (COSTA, 2005).

O projeto - que ficou conhecida como "PEC da Paradiplomacia" - não foi aprovado, pois o Deputado Federal Ney Lopes (PFL, RN), relator na Comissão de Constituição, Justiça e de Cidadania (CCJ), alegou que no ordenamento jurídico brasileiro não havia nada que impedisse os as unidades federadas de celebrarem atos internacionais ${ }^{29}$.

Entende-se, de acordo com Prazeres (2004), que tal parecer contradiz a orientação majoritária da doutrina constitucionalista brasileira e a consultoria jurídica do Itamaraty. Ademais, desconsiderou-se o fato de o princípio da legalidade possuir aplicação mais rigorosa para a administração pública do que para os particulares. Sendo assim, para que determinado ato seja legal, não basta que a lei não proîba a sua realização, ela deve expressamente autorizar a administração pública a fazê-lo. Diante do parecer negativo feito pela CCJ, órgão responsável por exercer o controle de constitucionalidade no processo legislativo, a PEC foi arquivada em janeiro de 2007.

Outra tentativa de normatizar a atuação internacional das unidades federadas brasileiras ocorreu em 2006, através de um Projeto de Lei

\footnotetext{
${ }^{29}$ Parecer do relator disponível em: $<$ http://www.camara.gov.br/proposicoes Web/prop_mostrarintegra?codteor=388392\&filename $=\mathrm{PRL}+1+\mathrm{C}$ CJC+\%3D\%3E+PEC+475/2005>. Acesso em 7 de novembro de 2014.
} 
Complementar (PLS) (n. 98/2006) ${ }^{30}$ apresentado pelo Senador Antero Paes de Barros (PSDB, MT). O objetivo desta proposição era regulamentar a aplicação de normas internacionais por unidades federadas do Brasil, como também o procedimento envolvendo a celebração, a execução, a eficácia, a aplicabilidade, a interpretação e a vigência dos tratados internacionais no país.

Durante a sua tramitação na Comissão de Relações Exteriores e Defesa Nacional (CRE), o relator do Arthur Virgílio (PSDB, AM) manifestou-se favorável à aprovação do projeto, sugerindo um ajuste no texto de modo a incluir a expressa possibilidade de as unidades federadas brasileiras celebrarem acordos internacionais, desde que mediante prévia autorização do MRE, através dos artigos $12^{31}$ e $13^{32}$ (RODRIGUES, 2011; BRANCO, 2009; BARROS, 2009). Este projeto, no entanto, foi rejeitado por unanimidade pela CCJ em maio de 2010, sob a alegação de inconstitucionalidade da matéria, sendo encaminhado para arquivamento ${ }^{33}$.

Apesar de considerar este requisito como uma importante forma de assegurar a compatibilidade dos convênios com o ordenamento jurídico e com a política externa, Branco (2009) alerta para a impossibilidade prática de o MRE apreciar a totalidade dos convênios assinados por todos os estados e municípios brasileiros. Rodrigues (2011), semelhantemente, considera positivo o fato de ele abarcar todos os entes federados, contudo, critica a necessidade de prévia autorização do MRE, considerado como restritivo e limitador das ações internacionais destes entes. Além disso, o autor considera que o PLS foi omisso em não contemplar o direito de consulta ou participação das unidades federadas

\footnotetext{
${ }^{30}$ Disponível em: <http://www.senado.leg.br/atividade/rotinas/materia/getPDF.asp?t=45693\&tp=1>. Acesso em 25 de outubro de 2015.

31 Artigo 12 - Os Estados, os Municípios e o Distrito Federal poderão, no âmbito de suas competências constitucionais, negociar e celebrar convênios com subunidades políticas ou administrativas estrangeiras mediante prévia autorização do Ministério das Relações Exteriores. § $1^{\circ}$ Os convênios internacionais mencionados no caput deste artigo não serão considerados tratados internacionais. $\S 2^{\circ}$ As obrigações que possam decorrer de um convênio internacional serão reguladas pela lei do Estado, Município ou Distrito Federal que o tenha firmado.

32 Artigo 13 - Convênio internacional negociado e celebrado por entes da Federação brasileira não pode contrariar acordo-quadro do qual o Brasil seja parte. $\S 1^{\circ}$ Se houver acordo-quadro pertinente, o ato negociado como objeto de convênio internacional deve constituir ajuste complementar àquele. $\S 2^{\circ}$ Se não houver acordo-quadro pertinente, mas o objeto de convênio internacional conflitar com competências federais, o ato negociado deve constituir tratado.

33 Parecer do relator dis ponível em:

$<$ http://www.senado.leg.br/atividade/rotinas/materia/getPDF.asp?t=77030\&tp=1 >. Acesso em $25 \mathrm{de}$ outubro de 2015.
} 
no processo de celebração de tratados quando estes afetarem seus interesses particulares e competências exclusivas ou comuns.

Mesmo diante da ausência de êxito das propostas apresentadas, o debate sobre a normatização da atuação internacional das unidades federadas brasileiras encontra-se longe de seu esgotamento. Atualmente, este tema é discutido nos encontros promovidos pela Subchefia de Assuntos Federativos (SAF) da Presidência da República (PR) - órgão destinado a promover a interlocução entre o Governo Federal e os Estados e Municípios.

Um primeiro grande marco desta discussão consistiu na realização do evento intitulado "COLÓQUIO FEDERATIVO - Cooperação Internacional Federativa: Marco legal e mecanismos institucionais", sediado em Brasília, em Outubro de 2011. Tal iniciativa contou com a participação de assessores internacionais de Estados, Municípios e do Governo Federal, e também de acadêmicos nacionais e internacionais e associações municipalistas. Neste evento, debateram-se propostas sobre os avanços jurídicos e institucionais para ação internacional dos governos subnacionais.

Com objetivo de atender a esta demanda, a SAF apresentou, na III Reunião da Cooperação Descentralizada ocorrida no dia 21 de agosto de 2013 em Brasília, uma proposta de minuta de decreto visando estabelecer procedimentos para as ações decorrentes de um ato federal, além da proposta de criar um Fórum de Gestores (FOCID).

Após discutir em alguns encontros os termos da minuta de decreto com as unidades federadas e demais instituições interessadas ali presentes ${ }^{34}$, consentiu-se em torno da proposta durante a $V$ Reunião da Cooperação Descentralizada, ocorrida no dia 25 de março de 2014 em Recife. Assim, houve encaminhamento formal do texto final da minuta às áreas jurídicas do MRE e da Casa Civil da Presidência da República para análise.

Enquanto a questão não avança no plano jurídico, as unidades federadas brasileiras seguem desempenhando uma série de iniciativas internacionais, sem que haja conflito com a Constituição Federal. Dentre elas podemos citar: o

\footnotetext{
34 Agência Brasileira de Cooperação (ABC), a Assessoria de Assuntos Federativos e Parlamentares (AFEPA), a Frente Nacional dos Prefeitos (FNP), a Confederação Nacional dos Municípios (CNM), entre outras.
} 
estabelecimento de escritórios permanentes ou centros de comércio no exterior; a hospedagem de representações de unidades federadas de outros países; a realização de viagens ao exterior para participar de missões, feiras ou eventos internacionais; a criação de zonas de cooperação sub-regiona|35; a participação de representantes municipais e estaduais em conferências, organizações internacionais, representações diplomáticas em capitais estrangeiras e até mesmo nas missões oficiais do governo brasileiro a países estrangeiros. Tais ações evidenciam o descompasso existente entre o plano jurídico-formal, que limita a atuação internacional das unidades federadas, e o plano empírico, no qual as unidades federadas se relacionam com o exterior de diversas formas (PRAZERES, 2004).

A respeito da cooperação internacional descentralizada, Rodrigues (2011) informa que, mesmo predominando no Brasil o entendimento jurisprudencial e doutrinário de que as relações exteriores são uma competência exclusiva da União, a própria União criou, ao longo dos últimos anos, espaços institucionais destinados ao desenvolvimento desta modalidade de cooperação envolvendo os governos não centrais, dentre eles: a Subchefia de Assuntos Federativos do Ministério de Relações Institucionais da Presidência da República (SAF), a Assessoria de Relações Federativas e Parlamentares (AFEPA) e a Agência Brasileira de Cooperação $(A B C)$, estas duas últimas no âmbito do Ministério das Relações Exteriores. Entende-se, assim, que a União passa a adotar uma mudança de postura, deixando de se opor às ações internacionais dos seus estados e municípios, o que aponta para o seu gradativo reconhecimento. Similarmente, Nunes (2005) alega que a posição do governo federal diante da atuação internacional das unidades federadas se alterou bastante ao longo dos anos, passando de uma postura de desconforto em face às experiências pioneiras do Rio de Janeiro (1983) e do Rio Grande do Sul (1987) até uma postura de aceitação e reconhecimento que predomina atualmente. Tal reconhecimento, no entanto, se dá apenas no plano político. No plano jurídico,

\footnotetext{
35 A exemplo do acordo envolvendo o Codesul e a Crecenea, do qual participam províncias argentinas (Chaco, Corrientes, Entre Rios, Formosa, Missiones e Santa Fé) e estados brasileiros (Mato Grosso do Sul, Paraná, Santa Catarina e Rio Grande do Sul)
} 
os compromissos celebrados ainda carecem de legalidade e segurança jurídica, o que apontaria para a necessidade da normatização.

Relativamente à discussão sobre a criação de um marco jurídico ser ou não imprescindível para a Cooperação Internacional Descentralizada ${ }^{36}$, Rodrigues (2011) apresenta duas respostas distintas com base na realidade do federalismo brasileiro. A primeira delas considera que o marco jurídico não é imprescindível, uma vez que os eventuais conflitos de competência entre a União e suas unidades federadas podem ser resolvidos na esfera política, através da diplomacia federativa promovida pela PR e pelo MRE. Segundo o autor, a experiência brasileira tem caminhado neste sentido, com o fortalecimento de órgãos que fomentam a interlocução e a coordenação entre os diferentes níveis da federação, a exemplo da SAF e da AFEPA. A segunda perspectiva, contrariamente, argumenta que um marco jurídico é imprescindível, uma vez que os agentes públicos que praticam a cooperação internacional descentralizada se pautariam pelo princípio da legalidade. Neste sentido, a falta de um marco jurídico gera insegurança e impede que várias ações sejam desempenhadas.

Em relação aos efeitos práticos desta lacuna normativa, alguns estados e municípios brasileiros costumam prestar contas à União somente após os atos já terem sido celebrados(LESSA, 2007). Além disso, nota-se que algumas unidades federadas brasileiras enfrentam dificuldades para justificar suas ações internacionais perante o Ministério Público (MP), os Tribunais de Justiça (TJs) e os Tribunais de Contas (TCs), que, ocasionalmente, questionam sua legitimidade (BARROS, 2009).

Diante destas questões, parte da academia e de agentes públicos vinculados a governos não centrais brasileiros defendem algum tipo de normatização (constitucional ou infraconstitucional) da paradiplomacia, como forma de institucionalizar esta prática, aumentando a sua autonomia para atuar na esfera internacional, evitando eventuais entraves com a União e conferindo segurança jurídica aos compromissos internacionais celebrados. Por outro lado,

\footnotetext{
${ }^{36}$ Embora a cooperação descentralizada seja apenas uma das áreas de atuação intern acional das unidades federadas brasileiras, entende-se que a sua regulamentação é prioritária pelo destaque que ela possui na agenda política dos estados e municípios e também porque a paradiplomacia financeira já se encontra prevista na Constituição Federal (artigo 52, V).
} 
destaca-se a consecução destes objetivos depende muito da forma como esta normatização será feita. Há, neste sentido, a possibilidade que tal medida restrinja ainda mais a paradiplomacia, tornando sua execução mais burocrática ao estabelecer, por exemplo, que todo e qualquer acordo internacional deva ser submetido à aprovação do MRE ou do Congresso (BARROS, 2009).

\section{CONSIDERAÇÕES FINAIS}

A partir da análise sobre os ordenamentos jurídicos e institucionais argentino e brasileiro em relação às possibilidades de atuação internacional de suas unidades federadas, apontam-se algumas conclusões, organizadas no Quadro 1:

Quadro 1. Federalismo e atuação internacional das unidades federadas na Argentina e no Brasil

\begin{tabular}{|c|c|c|}
\hline$\overbrace{\text { Categoria }}^{\text {Estado }}$ & Argentina & Brasil \\
\hline Unidades Federadas & $\begin{array}{c}\text { Províncias e Cidade } \\
\text { autônoma de Buenos } \\
\text { Aires }\end{array}$ & $\begin{array}{l}\text { Estados, municípios e } \\
\text { Distrito Federal. }\end{array}$ \\
\hline $\begin{array}{c}\text { Grau de autonomia dos } \\
\text { entes federados }\end{array}$ & $\begin{array}{c}\text { Federalismo } \\
\text { descentralizado }\end{array}$ & $\begin{array}{l}\text { Federalismo } \\
\text { centralizado. }\end{array}$ \\
\hline $\begin{array}{c}\text { Normatização da } \\
\text { inserção internacional } \\
\text { dos governos } \\
\text { subnacionais }\end{array}$ & $\begin{array}{l}\text { Art. } 124 \text { (celebração } \\
\text { de acordos e } \\
\text { convênios). }\end{array}$ & $\begin{array}{l}\text { Art. } 52 \text {, inciso V } \\
\text { (paradiplomacia } \\
\text { financeira). }\end{array}$ \\
\hline $\begin{array}{l}\text { Órgãos envolvidos no } \\
\text { processo decisório } \\
\text { (Nível Federal) }\end{array}$ & $\begin{array}{l}\text { - Congresso } \\
\text { Nacional }\end{array}$ & 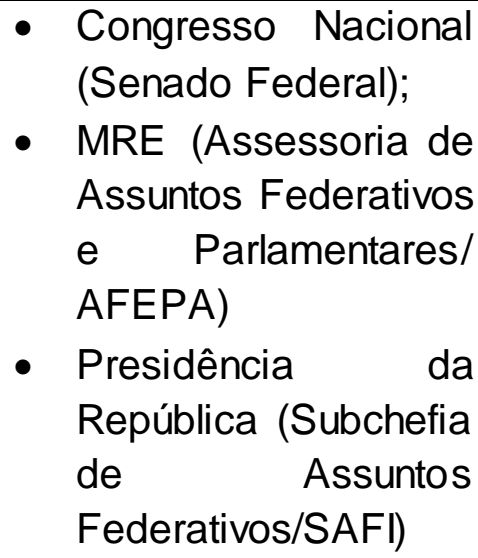 \\
\hline
\end{tabular}


históricos envolvendo a formação de cada federação resultaram em importantes consequências no grau de autonomia concedido as suas unidades federadas.

A Argentina, enquanto exemplo de federação centrípeta formada a partir da união de províncias até então soberanas, buscou conservar ao máximo a autonomia destas províncias, ainda que forças centralizadoras tenham prevalecido durante os regimes autoritários. Já o Brasil, enquanto exemplo de federação centrífuga formada através de um processo no qual o Estado unitário imperial foi descentralizado com a proclamação da República, apresentou uma tendência histórica de concentração de poderes e competências na União, um vício de origem que persistiu mesmo após os avanços promovidos pela Constituição de 1988, dentre os quais se destaca inclusão dos municípios como unidades federadas.

Outro achado é que, embora não exista no ordenamento jurídico brasileiro uma norma geral capaz de regulamentar todas as modalidades de atuação internacional de suas unidades federadas, algumas iniciativas já possuem respaldo legal. Destaca-se a paradiplomacia financeira, prevista no art. 52, inc. $\mathrm{V}$ da Constituição e regulamentada por outros instrumentos normativos, e a cooperação descentralizada desenvolvida com base em acordos-quadro celebrados entre o Brasil e Estados estrangeiros.

Com relação à normatização promovida pela Argentina, o fato de o art. 124 da Constituição versar sobre "convênios internacionais" de forma genérica faz com que haja um respaldo legal mais amplo, não se limitando a uma ou outra modalidade de convênio. Embora tal artigo represente um importante marco jurídico para a paradiplomacia argentina, sua redação provoca diversas divergências interpretativas, principalmente com relação aos requisitos necessários para a celebração dos atos internacionais.

Enquanto estas divergências não são solucionadas através de uma regulamentação, não é possível afirmar que o modelo argentino garanta uma segurança jurídica plena aos compromissos firmados pelas províncias no plano internacional. Diante da incerteza a respeito do significado exato da expressão "dar conhecimento ao Congresso nacional", também não é possível afirmar de forma absoluta que as províncias argentinas exerçam uma atuação internacional mais autônoma que os estados-membros brasileiros, uma vez que existe uma 
corrente doutrinária que interpreta a referida expressão no sentido de haver uma necessidade de estes convênios serem aprovados pelo Congresso, o que representaria uma forte ingerência por parte da União.

Por fim, considera-se que, apesar de não impedir na prática o exercício da paradiplomacia no Brasil, a ausência de uma norma geral expressa limita as possibilidades formais de atuação internacional das unidades federadas brasileiras, já que a ampla maioria dos acordos internacionais celebrados por estes atores não possuem força jurídica, restringindo-se ao âmbito da obrigação moral.

\section{Referências Bibliográficas}

ACCIOLY, Hildebrando. Manual de Direito Internacional Público. 11ª edição. Editora Saraiva: São Paulo, 1986.

ARGENTINA. Constitución de la nación Argentina: 1994. Disponível em: <http://infoleg.mecon.gov.ar/infoleglnternet/anexos/0-4999/804/norma.htm>. Acesso em de maio de 2015.

AZAMBUJA, Darcy. Teoria Geral do Estado. 37 ed. São Paulo: Globo, 1997.

BARROS, Mariana Andrade. Atuação Externa dos Governos Subnacionais: análise jurídica do caso brasileiro. Dissertação (Mestrado em Direito Público). Pontifícia Universidade Católica de Minas Gerais (PUC - MG): Belo Horizonte, 2009.

BONAVIDES, Paulo. O Caminho para um Federalismo das Regiões. In: Revista de Informação Legislativa. Brasília, 17, n. 65, jan-mar,1980

BRANCO, Álvaro Chagas Castelo. Paradiplomacia \& entes não-centrais no cenário internacional. Curitiba: Juruá, 2008

BRASIL. Constituição da República Federativa do Brasil de 1988. Disponível em: < http://www.planalto.gov.br/ccivil_03/Constituicao/Constituicao.htm>. Acesso em $15 \mathrm{de}$ julho de 2014.

CARBAJAL, Juan José; GASOL, Claudia. La gestión internacional de las provincias argentinas en el marco del sistema federal argentino a la luz de sus propias constituciones. In: Las Provincias Argentinas en el Escenario Internacional. Desafíos y obstáculos de un sistema federal. Buenos Aires, Programa de Naciones Unidas para el Desarrollo (PNUD), 2008.

COSTA, André. Prefácio. In: BRIGAGÃO, Clóvis. Relações Internacionais Federativas no Brasil: Estados e Municípios. Rio de Janeiro: Gramma, 2005. 
CRAWFORD, James. The International Law Commission's Articles on State Responsability - Introduction, Text and Commentaries. Cambridge: Cambridge University Press, 2005

DALLA VÍA, Alberto Ricardo. Derecho constitucional económico. Abeledo-Perrot: Buenos Aires, 1999.

DROM, Roberto; MENEM, Eduardo. La Constitución reformada. Ediciones Ciudad Argentina, Buenos Aires: 1994

DUCHACEK, Ivo. Comparative federalism: the territorial dimensions of politics. New York: Holt, Rinehart and Winston, 1970

DUCHACEK, Ivo. Perforated Sovereignties: Towards a Typology of New Actors in International Relations. In: MICHELMANN, Hans J.; SOLDATOS, Pana Y. Federalism and International Relations. The Role of Subnational Units. New York: Oxford University Press, 1990.

EKMEKDJIAN, Miguel. Tratado de derecho constitucional (Tomo V). Ediciones Depalma: Buenos Aires, 1999.

ELAZAR, Daniel. Exploring Federalism. Tuscaloosa: The University of Alabama Press, 1987.

IGLESIAS, Valeria. La dimensión internacional de los créditos directos del Banco Interamericano de Desarrollo y el Banco Mundial a las provincias. Notas del caso argentino.

In: IGLESIAS, Eduardo (director) et al. Las provincias argentinas en el escenario internacional. Desafíos y obstáculos de un sistema federal.1a ed. - Buenos Aires: Programa de las Naciones Unidas para el Desarrollo - PNUD, 2008.

KINCAID, John. Constituent Diplomacy in Federal Polities and the Nation-state: Conflict and Co-operation. In: MICHELMANN, H; SOLDATOS. Federalism and International Relations: the role of subnational units. Oxford: Clarendon Press, p. 54-74, 1990.

KUGELMAS, Eduardo; BRANCO, Marcello Simão. Os governos subnacionais e a nova realidade do federalismo. In: VIGEVANI, Tullo; WANDERLEY, Luiz Eduardo W. (orgs). Governos subnacionais e sociedade civil: integração regional e Mercosul. São Paulo: EDUC; Fundação Editora da UNESP; FAPESP, p. 161-188, 2005.

LAVIÉ, Humberto Quiroga; BENEDETTI, Miguel Ángel; CENICACELAYA, María de las Nieves. Derecho Constitucional Argentino. $2^{\mathrm{a}}$ edición actualizada por Humberto Quiroga Lavié. Santa Fé: Rubinzal - Culzoni Editores, 2009

LENZA, Pedro. Direito Constitucional Esquematizado. $13^{\mathrm{a}}$ ed. revista, atualizada e ampliada. São Paulo: Editora Saraiva, 2009.

LESSA, José Vicente da Silva. Paradiplomacia no Brasil e no Mundo: o poder de celebrar tratados dos governos não centrais. Viçosa: Ed. UFV, 2007.

LIJPHART, Arend. Modelos de democracia. Desempenho e padrões de governo em 36 países. Rio de Janeiro: Civilização Brasileira, 2003. 
MAIA, José Nelson Bessa. Paradiplomacia financeira dos estados brasileiros: evolução, fatores determinantes, impactos e perspectivas. Tese Doutorado. Universidade de Brasília: Brasília, 2012.

MARIANO, Karina Lilia Pasquariello; MARIANO, Marcelo Passini. As teorias de integração regional e os estados subnacionais. Impulso, Piracicaba, v. 13, n. 31, p. 4769, 2002.

MEDEIROS, Antonio Paulo Cachapuz de. Prefácio. In: LESSA, José Vicente da Silva. Paradiplomacia no Brasil e no Mundo: o poder de celebrar tratados dos governos não centrais. Viçosa: Ed. UFV, 2007.

MICHELMANN, Hans J. Conclusion. In: MICHELMANN, H; SOLDATOS. Federalism and International Relations: the role of subnational units. Oxford: Clarendon Press, 1990, p. 34-53

NUNES, Carmen Juçara da Silva. A paradiplomacia no Brasil: o caso do Rio Grande do Sul. Dissertação de Mestrado. Universidade Federal do Rio Grande do Sul: Porto Alegre, 2005.

PAIKIN, Damián. Integración Regional y Nuevos pactos Federales: El rol de los gobiernos

sub-nacionales en el MERCOSUR (Tese de Doutorado). Universidad de Buenos Aires: Buenos Aires, 2010. Disponível em: <http://www.ceurconicet.gov.ar/imagenes/IntegraciOnRegional.pdf>. Acesso em 30 de junho de 2014.

PATRONI, Viviana. Argentina. In: GRIFFITHS, Ann L. Handbook of Federal Countries. Montreal: McGill-Queen's University Press, 2005

PRAZERES, Tatiana Lacerda. Por uma atuação constitucionalmente viável das unidades federadas brasileiras ante os processos de integração regional. In: VIGEVANI, Tullo et al (org.). A dimensão subnacional e as relações internacionais. São Paulo: EDUC; Fundação Editora da UNESP; Bauru: EDUSC, 2004, p. 283-312.

REZEK, José Francisco. Direito dos Tratados. Rio de Janeiro: Forense, 1984.

REZEK, José Francisco. Direito internacional público: curso elementar. 13ª edição revisada e atual. São Paulo: Saraiva, 2011.

RODRIGUES, Gilberto Marcos Antônio. Marco jurídico para a cooperação internacional descentralizada. São Paulo: Frente Nacional de Prefeitos, 2011.

RODRIGUES, Gilberto Marcos Antônio. Relações internacionais federativas no Brasil. Revista Dados, Rio de Janeiro, v. 51, n. 4, p. 1015-1034, 2008

SARAIVA, José Flávio Sombra. A busca de um novo paradigma: política exterior, comércio

externo e federalismo no Brasil. Rev. Bras. Polít. Int, v. 47, n. 2, p. 131-162, 2004

SEITENFUS, Ricardo; VENTURA, Deisy. Direito Internacional Público. 4⿳亠丷a edição revista e ampliada. Porto Alegre: Livraria do Advogado Editora, 2006. 
SHAW, Malcolm N. International Law. 5. ed. Cambridge: Cambridge University Press, 2003

SOLDATOS, Panayotis. An Explanatory Framework for the study of Federated States as Foreign Policy Actors. In: MICHELMANN, H; SOLDATOS. Federalism and International Relations: the role of subnational units. Oxford: Clarendon Press, 1990, p. 34-53.

VARELA, Claudia Gabriela Gasol. Gobiernos Locales y gestión internacional. Aspectos constitucionales e ius internacionalistas aplicados al caso argentino. Buenos Aires: Consejo Argentino para las Relaciones Internacionales (CARI), 2010. Disponível em: http://www.cari.org.ar/pdf/presentacion_claudia_varela.pdf. Acesso em: 25 de abril de 2014

VIGEVANI, Tullo. Ciclos Longos e Cenários Contemporâneos da Sociedade Internacional. Revista Lua Nova, n. 46, 1999.

Recebido em 14 de agosto de 2017. Aprovado em 25 de novembro de 2017. 